\title{
Thermal Decomposition of Tricresyl Phosphate on Ferrous Surfaces
}

\author{
Arash Khajeh, ${ }^{\dagger}$ Fakhrul H. Bhuiyan, ${ }^{\dagger}$ Jon-Erik Mogonye, ${ }^{\ddagger}$ Rose A. \\ Pesce-Rodriguez, ${ }^{\ddagger}$ Stephen Berkebile, ${ }^{\ddagger}$ and Ashlie Martini ${ }^{*}, \dagger$ \\ $\dagger$ Department of Mechanical Engineering, University of California Merced \\ $\ddagger U . S$. Army Research Laboratory, Aberdeen Proving Ground \\ E-mail: amartini@ucmerced.edu
}




\section{Supporting Information}
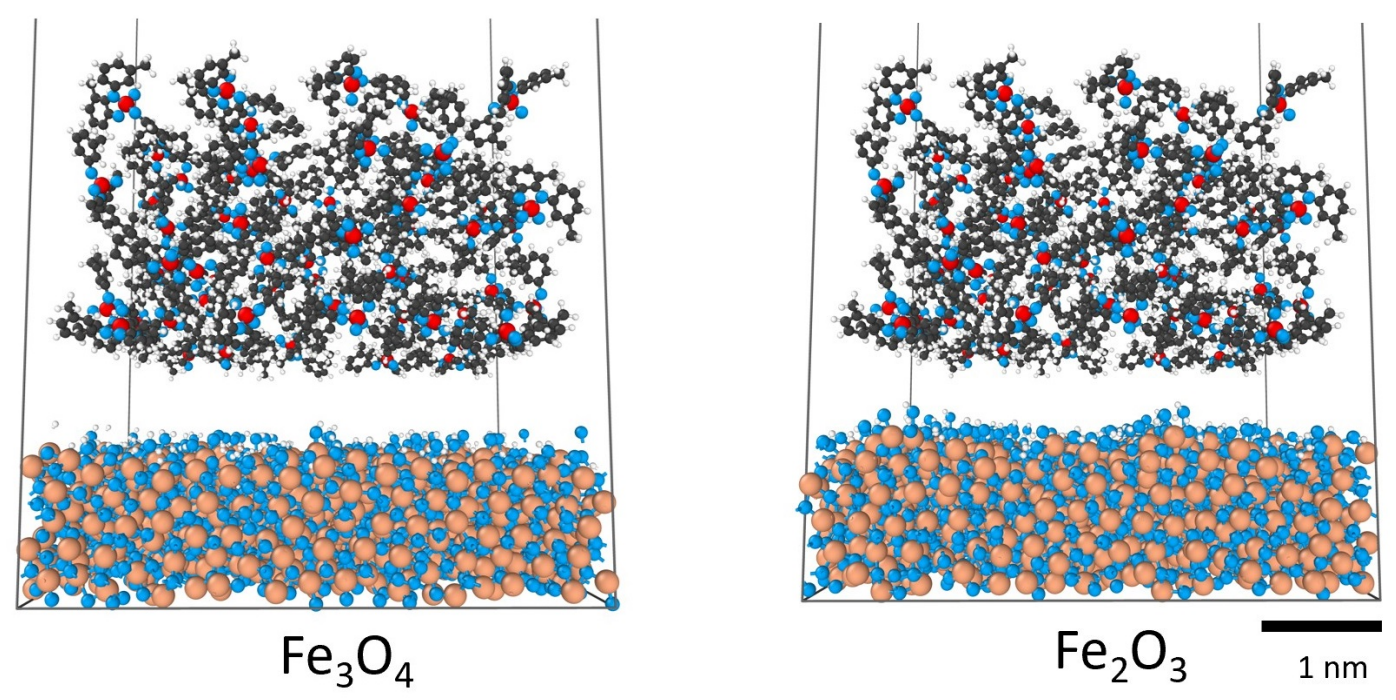

Figure S1: Perspective view snapshots of the two model systems comprising 64 TCP molecules on $\mathrm{OH}$ passivated $\mathrm{Fe}_{3} \mathrm{O}_{4}$, and $\mathrm{Fe}_{2} \mathrm{O}_{3}$ 


\section{$\mathrm{Fe}_{3} \mathrm{O}_{4}$}
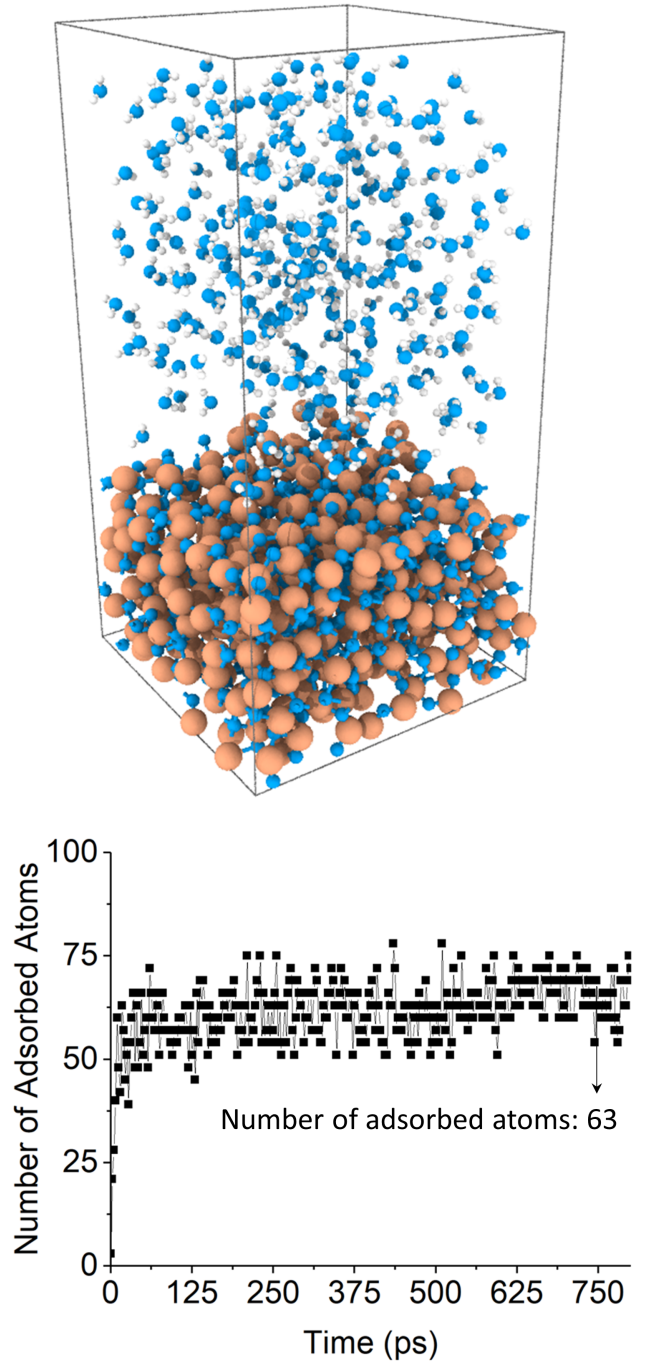

$\mathrm{Fe}_{2} \mathrm{O}_{3}$
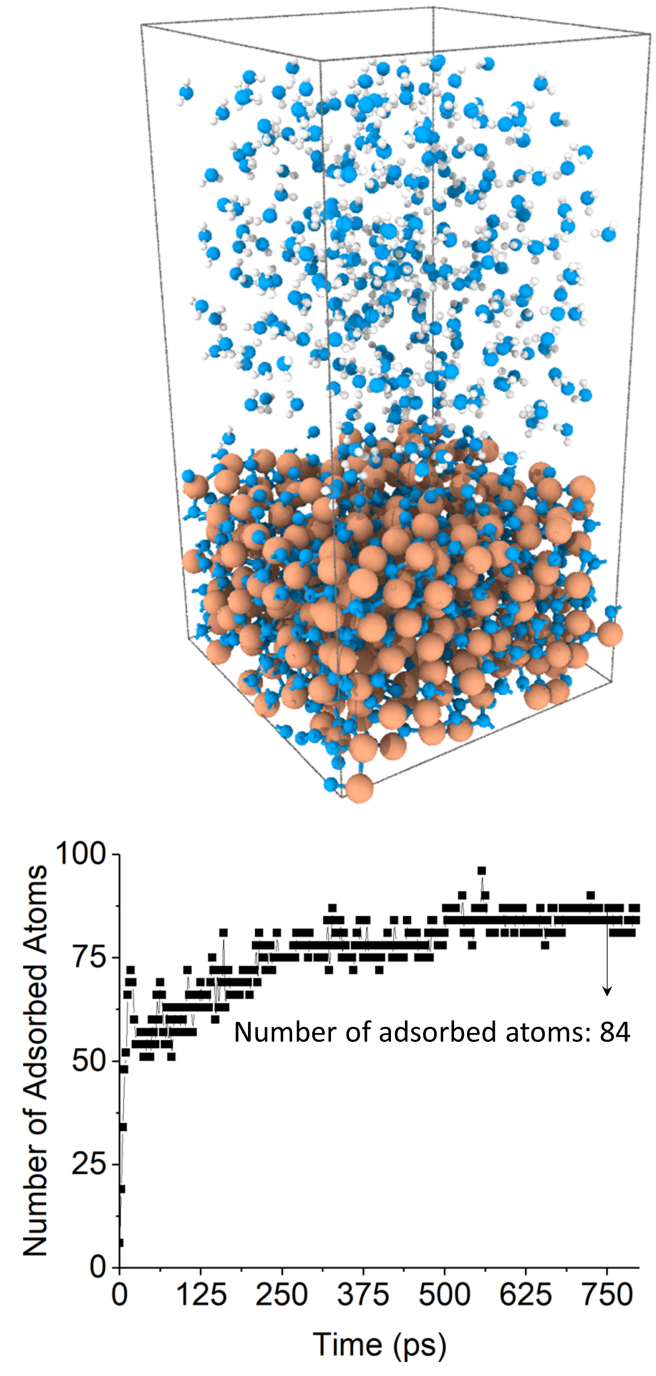

Figure S2: Change in the number of adsorbed atoms during the hydroxylation process for $\mathrm{Fe}_{3} \mathrm{O}_{4}$, and $\mathrm{Fe}_{2} \mathrm{O}_{3}$. The $\mathrm{Fe}_{2} \mathrm{O}_{3}$ surface bonded with 1.3 times more $\mathrm{H} / \mathrm{OH}$ than the $\mathrm{Fe}_{3} \mathrm{O}_{4}$ surface. 
(a)

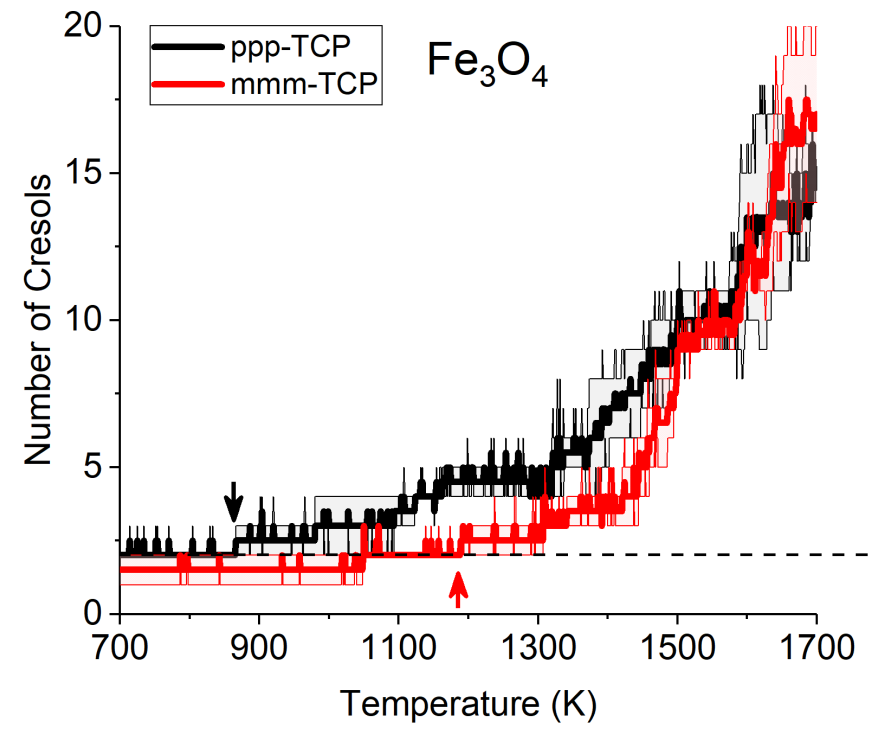

(b)

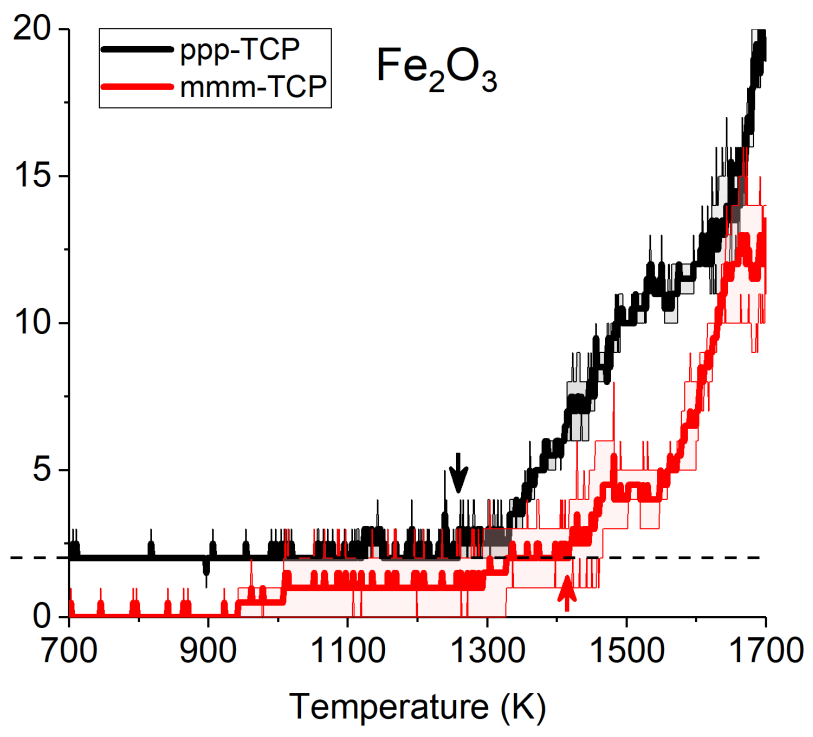

Figure S3: Comparison between the number of cresol groups produced from the decomposition of TCP in MD simulations with mmm-TCP and ppp-TCP on (a) $\mathrm{Fe}_{3} \mathrm{O}_{4}$ and (b) $\mathrm{Fe}_{2} \mathrm{O}_{3}$. The number of cresols from ppp-TCP is constantly higher than from mmm-TCP. The critical temperatures, identified by red and black arrows for ppp-TCP and mmm-TCP, respectively, correspond to the temperatures at which two cresols are first observed in the simulation. 

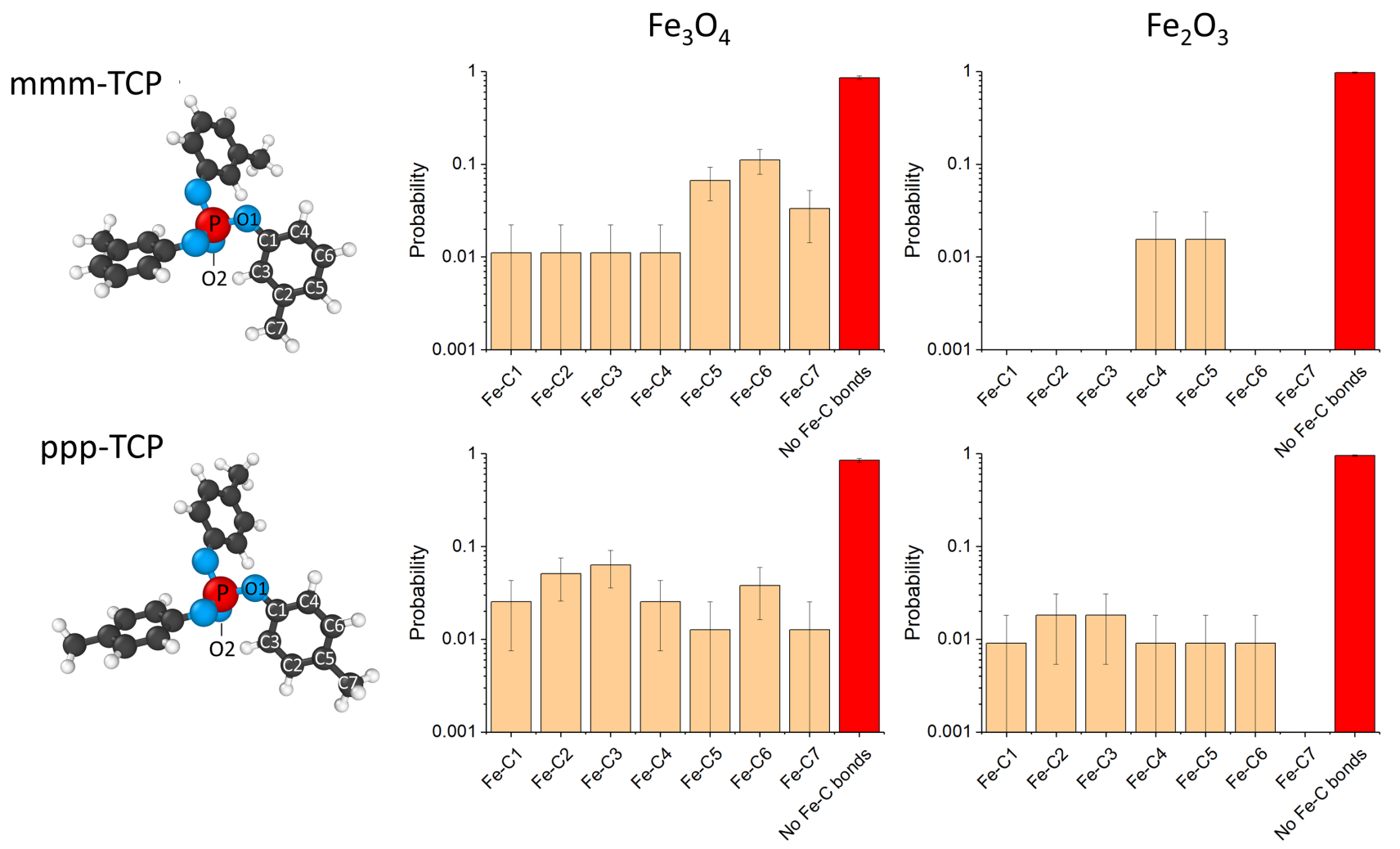

Figure S4: Statistical analysis of bonding between mmm-TCP (at the top) and ppp-TCP isomers (bottom) on $\mathrm{Fe}_{3} \mathrm{O}_{4}$ (left) and $\mathrm{Fe}_{2} \mathrm{O}_{3}$ surfaces (right) at the moment of cresol formation. Comparison between the two surfaces shows higher adsorption of ppp-TCP than mmm-TCP as well as a lower probability of TCP adsorption on the $\mathrm{Fe}_{2} \mathrm{O}_{3}$ surface that has the smaller $\mathrm{Fe} / \mathrm{O}$ ratio. In all cases, most of the cresols form through non-adsorption reaction pathways. 